\title{
Studies on the structure of hair-forming groups in Finnsheep
}

\author{
M. WOJCIKOWSKA-SOROCZYNSKA, D. SZTYCH and A. SWIDEREK \\ Warsaw Agricultural University, Department of Animal Breeding \\ and Animal Production Technology, Ul. Rakowiecka 26/28, \\ Warsaw, Poland
}

\begin{abstract}
Recognition of hair-forming groups in the skin of sheep was dealt with by many scientists on almost all breeds of sheep in the world and in some particular countries. To the few breeds not yet investigated up to now in this respect belongs Finnsheep (F), and this substantiates the present attempt.

The histological analysis was performed on skin sections taken by the biopsy method from $7 \mathrm{~F}$ of the Experiment Station Koluda Wielka.

Upon fixing and staining skin preparations by the method generally applied, the microscopic examination of kinds of groups, number of primary (P) and secondary (S) follicles per $1 \mathrm{~mm}^{2}$ $\left(\mathrm{nS} / \mathrm{mm}^{2}+\mathrm{nP} / \mathrm{mm}^{2}\right)$ in all kinds of groups as well as density of follicles, i.e. $\mathrm{nS} / \mathrm{nP}$ per $1 \mathrm{~mm}^{2}$, was carried out.

In microscopic pictures of skin, documented by means of photographs, superiority of triple groups, the share of which amounted to $74.2 \%$, has been found. The share of quadruple groups was $11.4 \%$, of double groups $8.6 \%$ and of hexal groups $5.1 \%$.

The mean density of follicles, measured by the number of primary and secondary follicles per $1 \mathrm{~mm}^{2}$ of skin, amounts to 14.1 , which results from the share of 2.0 primary +12.2 secondary follicles per $1 \mathrm{~mm}^{2}$.

The value of the $\mathrm{nS} / \mathrm{nP}$ ratio in particular groups was as follows: the highest ratio was for the triple group (6.0), in the double group it amounted to 5.8, in quadruple group to 5.6 and in the hexal group to 5.3. Thus, the mean density for this sheep breed amounts to 5.84 . Differences in the above values between singles and groups appeared to be small and not proved statistically.

The obtained results concerning the studied $\mathrm{F}$ skin traits are characteristics for the hair cover of longwoolled type.
\end{abstract}

Index words: Finnsheep, hair-forming, primary follicles, secondary follicles 